\title{
KOKEITA AUTOMAATTIRUOKINNAN JÄRJESTÄMISEKSI MEIJERISIKALASSA. II
}

\author{
P. SaArinen, E. Syrjänen ja Vuokko Hyvärinen \\ Helsingin Yliopiston Kotieläintieteellinen laitos, Viikin koetila, Malmi
}

Saapunut 22. 1. 1958.

Aikaisemman koesarjan nojalla tämän kirjoittajat totesivat (1958), että meijerisikaloissa voidaan väkirehujen syöntiä tarvittavassa määrin rajoittaa ja heran kulutusta nostaa lisäämällä kuivarehuautomaateista vapaasti syötettävään väkirehuseokseen $5-15 \%$ heinäjauhoja tai kuivattua sokerijuurikasleikettä. Edullisimman tuloksen ko. koesarjassa saavutti koeryhmä 3 , jonka väkirehuseoksen raakakuitupitoisuus oli heinäjauholisällä nostettu korkeimmaksi vastaten noin 7.7 prosenttia ilmakuivan seoksen painosta. Kun koesikojen ravinnontarpeesta tyydytettiin kuitenkin lähes puolet heralla, niin koko rehuannoksen kuiva-aineen raakakuitupitoisuus oli tällöin vielä pienempi kuin mitä aikaisemmin on esitetty raakakuidun optimimääräksi sian rehuannoksessa $(1,2$,$) . Tämän huomioonottaen oli$ mielenkiintoista todeta, mikä vaikutus rehuannoksen raakakuitupitoisuuden edelleen nostamisella oli kasvatustuloksiin. Lisäksi oli syytä tarkistaa, johtuiko heinäjauholisällä saatu edullinen tulos ensisijaisesti rehuannoksen sopivammasta raakakuitupitoisuudesta tai täyttävyydestä vaiko mahdollisesti heinässä olevista muista kasvutekijöistä, kuten tuntemattomasta ruohofaktorista jne. Samassa yhteydessä katsottiin olevan syytä kokeilla myös, missä määrin heran kuivattaminen lisää heran käyttömahdollisuuksia, etenkin kasvatuksen alkuvaiheessa, jolloin runsas heran käyttö helposti aiheuttaa sioille ruoansulatushäiriöitä. Näitten seikkojen edelleen selvittämistä varten kirjoittajat järjestivät uuden ruokintakokeen Meijerien Keskusosuusliike Valion Ylitornion meijerin sikalassa talvikautena 1956-1957.

\section{Kokeen järjestely}

Perusrehu suunniteltiin edellistä jonkinverran kuitupitoisemmaksi, ja siihen yritettiin sisällyttää myös ne toistaiseksi tuntemattomat kasvutekijät, joita paitsi herassa oletetaan esiintyvän ruohoissa ja kalajauhoissa. Tässä mielessä heinäjauhot sisällytettiin itse perusrehuun, ja kalajauhojen määrä rehuseoksessa nostettiin 5 pro- 
senttiin. Viimeksi mainitulla toimenpiteellä haluttiin varmistaa myös eläinten valkuaistarpeen tyydyttäminen runsaampiakin määriä raaakakuitua ja sulamattomia aineita saavalla koeryhmällä. Väkirehuseoksen raakakuitupitoisuutta, alunperin noin $6.9 \%$, nostettiin yhdellä ryhmällä noin $40 \mathrm{~kg}$ :n elopainorajasta alkaen, ja se suoritettiin lisäämällä perusrehusẹokseen kaurankuorijauhoja. Vertailtavina olivat seuraavat ruokinnat: a) perusrehu ynnä tuore hera, b) perusrehu + kaurankuorijauho ynnä tuore hera sekä c) perusrehu - kuivaheraseos ynnä vesi.

Koe suoritettiin 11.11. 1956 ja 15. 4. 1957 välisenä aikana kolmella 11 porsaan ryhmällä. Kokeeseen otettiin porsaat sikalaan samanaikaisesti tulleista porsaslähetyksistä siten, että kuhunkin ryhmään valittiin alkuperänsä, sukupuolensa, painonsa ja ulkonäkönsä puolesta mahdollisimman tarkoin toisiaan vastaavat porsaat. Tässä kokeessa oli kaikilla ryhmillä automaattiruokinta. Eläimet saivat syödä rehua vapaasti. Hera annettiin kaukaloista, ja jäljelle jäänyt määrä mitattiin kerran päivässä. Vettä annettiin tarpeen mukaan useampia kertoja päivässä. Eläinten punnitus suoritettiin kerran viikossa.

\section{Ruokinta}

Ruokintasuunnitelma tehtiin alunperin samoilla perusteilla kuin aikaisemminkin (taul. 1 ja 3). Perusrehun ja heran lisäksi porsaille annettiin tämän suunnitelman mukaan kuorittua maitoa 21 päivässä 25 kilon elopainorajaan saakka, jonka jälkeen määrä alennettiin 1 litraan päivässä. Kuoritun maidon määrän vähentymisen jälkeen porsaissa todettiin kuitenkin alakuloisuutta ja nuutuneisuutta. Häiriöiden välttämiseksi kuoritun maidon määrä palautettiin entiselleen eli 2 litraan vielä 2 viikon ajaksi, jonka jälkeen ryhdyttiin uudelleen seuraamaan alkuperäistä ruokintasuunnitelmaa.

Kivennäislisänä perusrehuseoksessa käytettiin $2 \%$ Keskusosuusliike Hankkijan Hera-rehusuolaseosta, jonka kokoomus oli seuraava:

$\begin{array}{lr}\text { Rehuliitua } & 40.000 \% \\ \text { Ruokintakalkkia } & 20.000, \\ \text { Rehufosfaattia } & 30.000, \\ \text { Ruokasuolaa } & 8.720, \\ \text { Rautasulfaattia } & 0.600, \\ \text { Magnesiumsulfaattia } & 0.500, \\ \text { Kuparisulfaattia } & 0.065, \\ \text { Mangaanisulfaattia } & 0.100, \\ \text { Kobolttisulfaattia } & 0.010, \\ \text { Kaliumjodidia } & 0.005,\end{array}$

Vitamiinitarpeen tyydyttämisen varmistamiseksi perusrehuun otettiin myös $1 \%$ Vaasan Höyrymylly Oy:n valmistamaa Kasvu-teho vitamiinivalmistetta, josta oli voimassa seuraava vitamiinitakuu:

$\begin{array}{lc}\text { A-vitamiinia } & 500.000 \mathrm{ky} / \mathrm{kg} \\ \mathrm{D}_{3} & 70.000 \\ \mathrm{E} & 250 \mathrm{mg} / \mathrm{kg} \\ \mathrm{B}_{2} & 200 \\ \mathrm{~B}_{12} & 0.4\end{array}$


Edellä mainitut lisät mukaanluettuina vertailuryhmän, R1, saaman perusrehun kok oomus oli seuraava:

$\begin{array}{llll}\text { Vehnänlesettä } & 20 \% & \text { Kalajauhoja } & 5 \% \\ \text { Kaurajauhoja } & 22, & \text { Heinäjauhoja } & 5, \\ \text { Maissijauhoja } & 20, & \text { Kasvu-tehoa } & 1, \\ \text { Ohrajauhoja } & 25, & \text { Hera-rehusuolaseosta } & 2,\end{array}$

Ryhmä 2 sai seosta, jossa oli $50 \%$ ylläolevaa perusrehua ja $50 \%$ kuivattua heraa ynnä lisäksi vettä vapaasti.

Perusrehun suhteellisen runsaasta raakakuitupitoisuudesta huolimatta yhdelle koeryhmälle (R 3) lisättiin $40 \mathrm{~kg}$ :n painorajasta alkaen perusrehuun $10 \%$ kaurankuorijauhoja, niin että kuivarehuseoksen raakakuitupitoisuus nousi alkuperäisestä $6.9 \%$ :sta $9.2 \%:$ iin.

Koerehuseokset valmistettiin Keskusosuusliike Hankkijan Kolpin sekoittamossa, ja rehuanalyysit suoritettiin Valtion maatalouskemiallisessa laboratoriossa. Näiden koostumus ja lasketut ry-arvot on yksityiskohtaisemmin esitetty taulukossa 1.

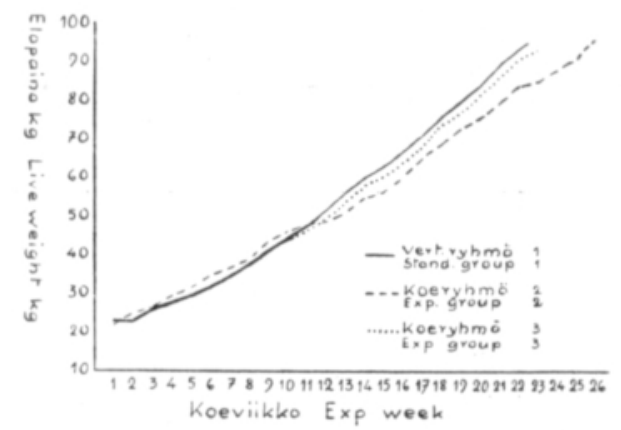

Kuvio 1. Keskimääräinen lisäkasvu ryhmittäin.

Fig 1. The average weight increase per each group.

\section{Koetulokset}

Porsasryhmien kasvun kehitys on esitetty kuviossa 1. Ryhmästä 1 eli perusrehuryhmästä jouduttiin kokeen aikana poistamaan yksi eläin sen sairastuttua keuhkotulehdukseen. Ryhmässä 2 oli kokeen loppuvaiheessa havaittavissa kasvun hidastumista. Se johtui myös ehkä siitä, että sikalassa vallinneen tilanpuutteen takia nämä porsaat jouduttiin kesken koetta siirtämään pienempään karsinaan, jossa rehuautomaatille pääsy ei ollut heikommille sioille aivan yhtä helppoa kuin suuremmassa karsinassa.

Heran kulutus jäi molemmilla tuoretta heraa saavilla ryhmillä (R 1 ja $R 3$ ) melko vähäiseksi. Tähän lienee 'syynä ollut talviaikana heran kylmyys ja eläinten taipumus liata juotavaksi tarjottu hera hetimiten kun uusi annos annettiin.

Kuviosta 1 ilmenee, että koe-eläinten kasvunopeus oli $50 \mathrm{~kg}: \mathrm{n}$ elopainoon saakka kaikissa ryhmissä suunnilleên sama. Tämän jälkeen alkoi kuivaheraryhmä jäädä huomattavasti jälkeen, ja se oli teuraskuntoinen vasta 4 viikkoa myöhemmin kuin muut rybmät. 
Ryhmien keskimääräiset lisäkasvut on esitetty taulukossa 2 ja rehunkulutus suhteessa elopainon lisäykseen taulukossa 3 . Lisäkasvuja verrattaessa on huomattava, mitä edellä on mainittu kuivaheraryhmän siirrosta kokeen loppuvaiheessa.

Teurastustulokset ja keskimääräinen rehunkulutus kiloa kohden teuraspainonlisäystä on esitetty taulukossa 4. Viimeksi mainittu luku on saatu vähentämällä lopullisesta teuraspainosta $65 \%$ eläimen alkupainosta. Teurasarvostelun suoritti kokeen hoitaja agr. Vuokko Hyvärinen maist. J. Partasen antamien ohjeiden mukaisesti.

Taulukko 1. Koerehujen koostumus ja lasketut ry-arvot.

Table 1. The chemical ccmposition of the feeds and the calculated net energy values.

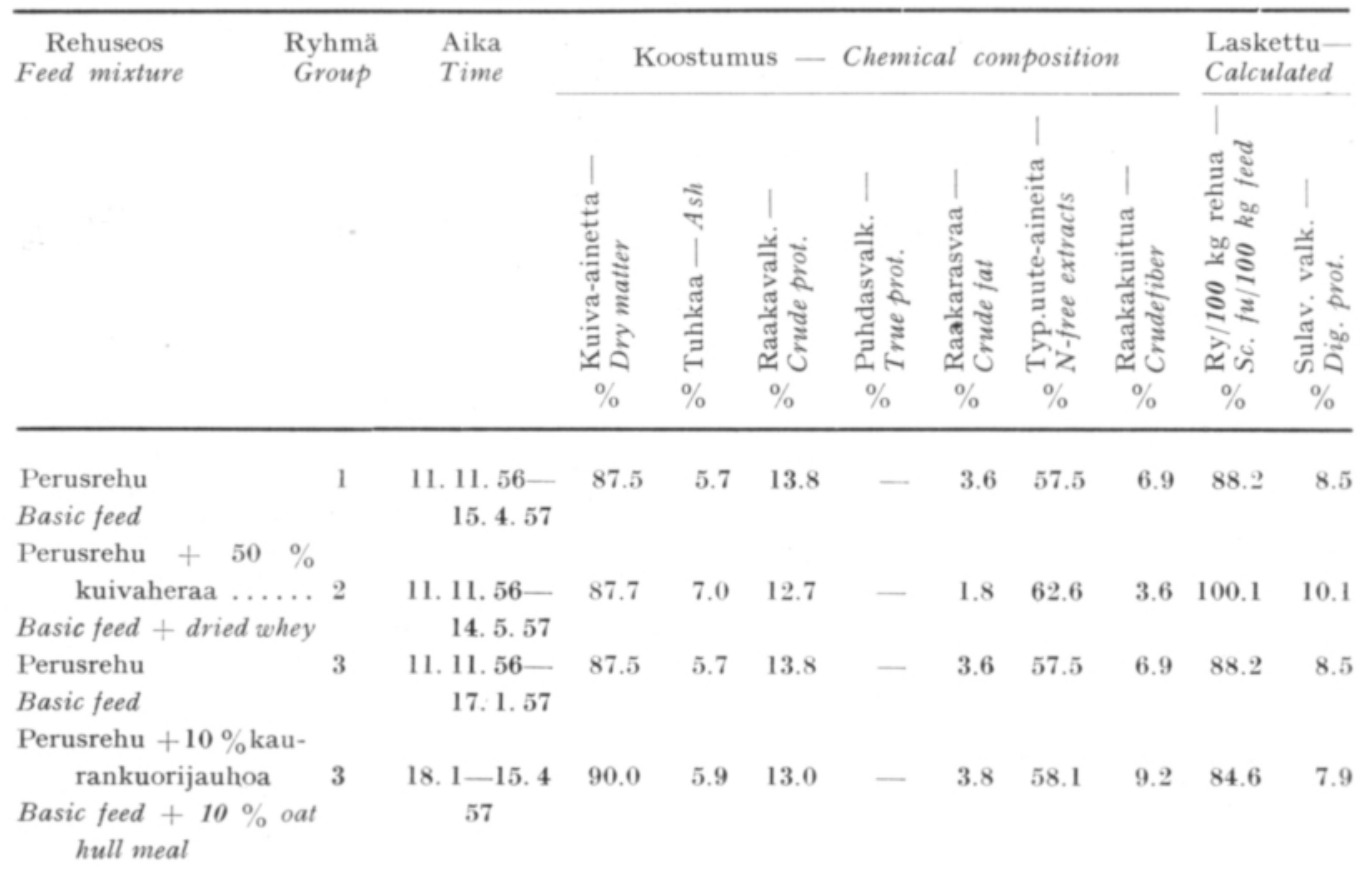

Taulukko 2. Lisäkasvu ryhmittäin.

Table 2. Weight increase in average per each group.

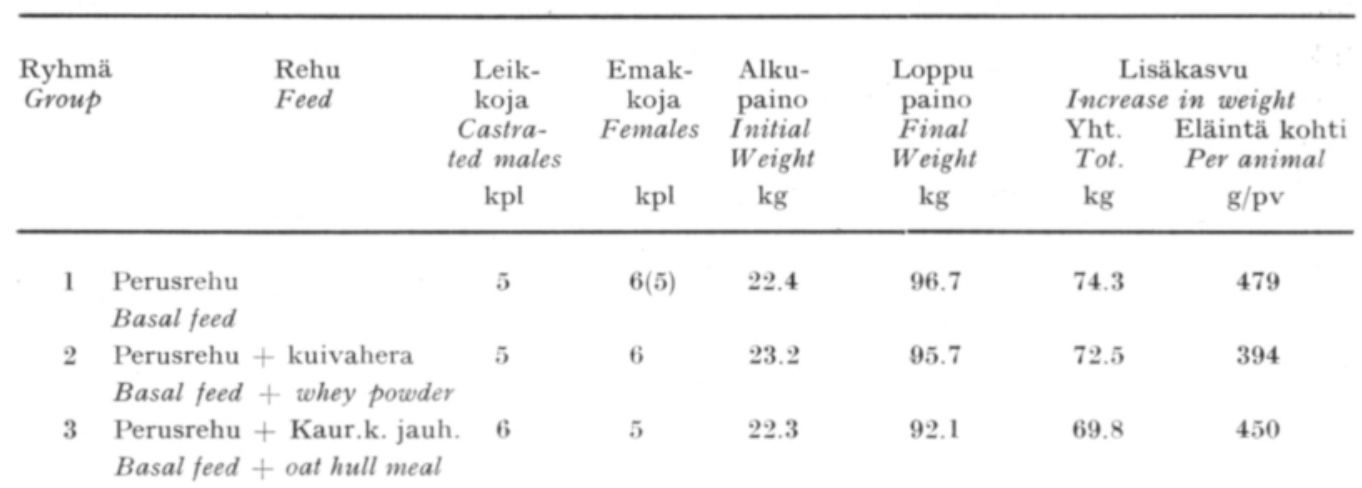


Taulukko 3. Rehunkulutus.

Table 3. Feed consumption.

\begin{tabular}{|c|c|c|c|c|c|c|c|}
\hline \multirow[t]{3}{*}{$\begin{array}{l}\text { Ryhmä } \\
\text { Group }\end{array}$} & \multirow{3}{*}{$\begin{array}{c}\text { Ruokinta- } \\
\text { päiviä } \\
\text { Days fed }\end{array}$} & \multicolumn{3}{|c|}{$\begin{array}{l}\text { Rehunkulutus } \\
\text { Feed consumption }\end{array}$} & \multicolumn{2}{|c|}{$\begin{array}{l}\text { Rehussa yht. } \\
\text { In total }\end{array}$} & \multirow{3}{*}{$\begin{array}{c}\text { Lisäkasvukiloa } \\
\text { kohden ry } \\
\text { Per each kg } \\
\text { weight increase }\end{array}$} \\
\hline & & $\begin{array}{l}\text { Kuor. } \\
\text { maitoa }\end{array}$ & $\begin{array}{l}\text { Heraa } \\
\text { Whey }\end{array}$ & $\begin{array}{l}\text { Väkirehua } \\
\text { Dry feed }\end{array}$ & $\begin{array}{c}\text { Ry } \\
\text { Sc.fu. }\end{array}$ & $\begin{array}{c}\text { Sv } \\
\text { Dig. prot. }\end{array}$ & \\
\hline & & $\mathrm{kg}$ & kg & kg & & $\mathrm{kg}$ & \\
\hline 1 & 155 & 93 & 1191.6 & 222.8 & 297.9 & 31.35 & 4.00 \\
\hline 2 & 184 & 86 & - & 244.7 & 255.2 & 27.38 & 3.20 \\
\hline 3 & 155 & 93 & 1187.0 & 227.7 & 290.8 & 30.65 & 4.16 \\
\hline
\end{tabular}

Taulukko 4. Teurastustulokset ja rehunkulutus suhteessa laskettuun teuraspainon lisäykseen.

Table 4. Dressing results and the feed consumption in proportion to the calculated increase in the carcass weight.

\begin{tabular}{|c|c|c|c|c|c|c|c|c|c|}
\hline \multirow[t]{2}{*}{$\begin{array}{c}\text { Ryhmä } \\
\text { Group }\end{array}$} & \multirow{2}{*}{$\begin{array}{c}\text { Elopaino } \\
\text { Live } \\
\text { weight } \\
\text { kg }\end{array}$} & \multirow{2}{*}{$\begin{array}{l}\text { Teuras- } \\
\text { paino } \\
\text { Careass } \\
\text { weight } \\
\quad \text { kg }\end{array}$} & $\begin{array}{l}\text { Teurastus- } \\
\text { tappio } \\
\text { Lost in } \\
\text { dressing }\end{array}$ & \multicolumn{4}{|c|}{$\begin{array}{l}\text { Selkäsilavan paksuus } \\
\text { cm } \\
\text { Thickness of back fat } \\
\mathrm{cm}\end{array}$} & \multirow[t]{2}{*}{$\begin{array}{l}\text { Lihak- } \\
\text { kuus } \\
\text { Lean } \\
\text { to fat } \\
\text { points }\end{array}$} & \multirow{2}{*}{$\begin{array}{c}\mathrm{Ry} / \mathrm{kg} \\
\text { teuras- } \\
\text { painon lis. } \\
\text { Sc.fu/kg } \\
\text { increase } \\
\text { in carcass } \\
\text { weight. }\end{array}$} \\
\hline & & & kg & 1 & 2 & 3 & $\begin{array}{l}\text { keskim. } \\
\text { Average }\end{array}$ & & \\
\hline 1 & 96.7 & 72.0 & $25.4 \quad 24.5$ & 4.3 & 2.7 & 3.1 & 3.4 & 12.2 & 5.1 \\
\hline 2 & 95.7 & 71.0 & $24.8 \quad 26.1$ & 4.1 & 2.5 & 2.9 & 3.2 & 12.4 & 4.6 \\
\hline 3 & 92.1 & 67.3 & $24.8 \quad 27.1$ & 4.5 & 2.4 & 3.0 & 3.3 & 12.4 & 5.5 \\
\hline
\end{tabular}

\section{Koetulosten tarkastelua}

Aikaisemmin suoritetuissa kokeissa tultiin sellaiseen tulokseen, että heraruokinnalla olevien sikojen kuivarehuun voidaan haitatta lisätä kuitupitoista rehua. Tämän mukaisesti nyt suoritetun kokeen perusrehuun lisättiin $5 \%$ heinäjauhoja, mutta lisäksi yhden koeryhmän rehuseokseen $40 \mathrm{~kg}$ :n elopainorajasta lähtien $10 \%$ kaurankuorijauhoa. Täten kuivarehun lopullinen kuitupitoisuus oli melko korkea eli $9.2 \%$. Tämäkään raakakuitulisä ei kuitenkaan näyttänyt vielä sanottavasti hidastavan eläinten kasvua, mutta toisaalta kaurankuorijauho ei myöskään sanottavasti pienentänyt väkirehun syöntiä. Teurasarvostelussa havaittiin selkäsilavan paksuuden olevan kaurankuori-ryhmällä suunnilleen sama kuin perusrehu-ryhmällä. Kokonaisrehunkulutus oli tällä ryhmällä hieman pienempi, mutta suhteessa painonlisäykseen suurempi kuin perusrehuryhmällä.

Rehunkulutusta laskettaessa ei ole otettu huomioon sitä rehumäärää, jonka eläimet mahdollisesti tuhlasivat. Kokeen alussa ei tuhlausta esiintynyt, mutta loppuvaiheessa, karsinatilan käydessä ahtaammaksi, joinakin päivinä esiintyi huomattavaakin rehun tuhlausta. Jos tämä tuhlaus otetaan huomioon, niin kokeen tuloksia arvosteltaessa päästään jonkinverran edellä mainitța edullisimpiin tuloksiin rehun hyväksikäytössä.

Rehun hyväksikäytön kannalta edullisin tulos saatiin kuivaherarehulla, vaikka tässä tapauksessa lisäkasvu oli suhteellisesti hitain. 


\section{$Y$ hteenveto ja päätelmät}

Meijerien Keskusosuusliike Valion Ylitornion meijerin sikalassa suoritetuissa toisen vuoden ruokintakokeissa, joissa oli verrattavana a) perusrehu ynnä tuore hera, b) perusrehu + kaurankuorijauholisä ynnä tuore hera sekä c) perusrehu ynnä kuivattu hera, saatiin seuraavat tulokset.

Kun kuivarehuseoksen raakakuitupitoisuus nostettiin $6.9 \%$ :sta $9.2 \%$ :iin lisäämällä 40 kilon elopainorajasta alkaen perusrehuun $10 \%$ kaurankuorijauhoja, tämä toimenpide ei pienentänyt kuivarehun eikä lisännyt heran kulutusta. Seurauksena oli jonkinverran pienempi lisäkasvu ja suurempi suhteellinen rehunkulutus kuin vertailuryhmällä. Osittain tämä tulos voi johtua siitä, että heran kulutus jäi tässä kokeessa odotettua pienemmäksi eli vain noin 1200 kiloon eläintä kohden.

Kun tuoreen heran sijasta käytettiin kuivattua heraa $50 \%$ kuivarehuseoksessa, niin kokeen alkuvaiheessa $45 \mathrm{~kg}: \mathrm{n}$ elopainorajaan saakka kuivatulla heralla näytti olevan kasvunopeuteen ja rehun hyväksikäyttöön edullisia vaikutuksia tuoreeseen heraan verrattuna. Suuremmille sioille syötettynä kuivattu hera taas osoittautui eläinten kasvunopeuden nojalla arvostellen vähemmän edulliseksi, mutta tällöinkin kuivatulla heralla saavutettiin kuitenkin käytettyä ry:ä kohden keskimäärin suhteellisesti parempi tuotantovaikutus kuin tuoreella heralla.

\section{KIRJALLISUUTTA}

(1) Axelsson, Joel \& Eriksson, Sture, 1953. The optimum crude fiber level in ration of growing pigs. J. Animal. Sci. 12: 881-891.

(2) NoRDFeldi, S., 1946. Försök med stigande mängder växttråd i fodret till växande gödsvin. Landbr. högsskolans husdjförs. anst. Förb. medd. 57. Norrtälja.

(3) SaArinen, P., SyrJänen, E. \& Hyvärinen, VuokKo, 1956. Kokeita automaattiruokinnan järjestämiseksi meijerisikalassa. Maatal.tiet. aikak. 28: 191-202.

S U M M A R Y :

EXPERIMENTS ON THE AUTOMATIC FEEDING SYSTEM IN CHEESE PLANT PIGGERIES. II.

P. SAARINEN, E. SYRJÄNEN and VUOKKo HYVÄrineN

Department of Animal Husbandry, University of Helsinki

In the second year of feeding experiments carried out at the piggery belonging to the Finnish Cooperative Dairies Association Valio creamery at Ylitornio comparisons were made of (a) the basic feed combined with fresh whey, (b) the basic feed + an addition of oat hull meal, combined with fresh whey, and (c) the basic feed combined with dried whey, giving the following results.

When the raw fibre content of the dry feed mixture was raised from $6.9 \% \mathrm{t} 09.2 \%$ by adding $10 \%$ oat hull meal to the basic feed for $40 \mathrm{kgs}$ live weight uppwards, this did not decrease the consumption of dry feed nor did it increase the consumption of whey. The results were a somewhat less additional growth and a higher ratio of feed consumption than in the standard group. This may be partly due to the fact that the consumption of whey in this test was smaller than expected, or only about $1200 \mathrm{~kg}$ per animal.

When dried whey was used instead of fresh whey, making up $50 \%$ of the dry feed mixture, at the beginning stages of the experiment up to $45 \mathrm{~kg}$ live weight it appeared to have a favourable effect on the rate of growth and the utilisation of the feed as compared with the effect of fresh whey. In larger pigs fed on dried whey the rate of growth of the animal appeared to be less favourable in comparison, but here also the dried whey had, on the average, a relatively better production effect per Scandinavian feed unit than the fresh whey. 